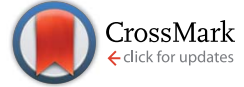

Cite this: RSC Adv., 2017, 7, 1735

Received 20th October 2016 Accepted 21st December 2016

DOI: $10.1039 / c 6 r a 25512 d$

www.rsc.org/advances

\section{Direct determination of graphene amount in electrochemical deposited Cu-based composite foil and its enhanced mechanical property}

\author{
Gongsheng Song, ${ }^{a}$ Zhongchi Wang, ${ }^{a}$ Youning Gong, ${ }^{a}$ Yanpeng Yang, ${ }^{a}$ Qiang Fu ${ }^{a b}$ \\ and Chunxu Pan*ab
}

The amount of graphene $(\mathrm{Gr})$ in a composite plays a key role in enhancing the performance of the composite. In general, an indirect method, that is, by adjusting the concentration of Gr (or GO) in the electrolyte, is used to study the influence of the graphene content on the properties of copper $(\mathrm{Cu})-\mathrm{Gr}$ composite foil. In this paper, we firstly propose a direct and accurate approach, that is, by using an instrumental carbon and sulfur analyzer, to determine the amount of $\mathrm{Gr}$ in the direct current electrodeposited $\mathrm{Cu}-\mathrm{Gr}$ composite foil, and also obtain the relationship between the amount of $\mathrm{Gr}$ in the composite foils and the concentration of $\mathrm{GO}$ in the electrolyte. Further, mechanical property measurements reveal that: (1) the variations in the mechanical properties (involving the elastic modulus, hardness and tensile strength) of the $\mathrm{Cu}-\mathrm{Gr}$ foils along with the concentration of $\mathrm{GO}$ in the electrolyte exhibit similar tendencies to that of the $\mathrm{Gr}$ content in the $\mathrm{Cu}-\mathrm{Gr}$ foils. (2) According to current experimental conditions, the optimal values of the mechanical properties and the amount of $\mathrm{Gr}$ in the foils appears at a GO concentration of $0.5 \mathrm{~g} \mathrm{~L}^{-1}$ in the electrolyte. (3) When the GO concentration is less than $0.5 \mathrm{~g} \mathrm{~L}^{-1}$, the values of the mechanical properties and the amount of $\mathrm{Gr}$ in the foils present an approximately linear relationship; and beyond $0.5 \mathrm{~g} \mathrm{~L}^{-1}$, the values become unstable and declining, which can be attributed to an agglomeration of excess GO in the electrolyte which makes it difficult to be co-deposited into the foil.

\section{Introduction}

Graphene (Gr), which emerged recently as a new carbon material with a one-atom thick $2 \mathrm{D}$ layer structure, has been recognized as an attractive reinforcing phase due to its unique and excellent physical, chemical and mechanical properties. ${ }^{1}$ In general, Gr reinforced metal composites can improve numerous properties of metals, such as: hardness, elastic modulus, tensile strength, corrosion resistance, and wear resistance, ${ }^{2-4}$ which indicates an important prospect for the application of $\mathrm{Gr}$ in the field of composites.

So far, various metals including stainless steel, ${ }^{5} \mathrm{Au},{ }^{6} \mathrm{Pt},{ }^{7} \mathrm{Ag},{ }^{8}$ $\mathrm{Ti}^{9}{ }^{9}$ and $\mathrm{Cu}^{10}$ have been used to prepare $\mathrm{Gr}-$ metal composites by using different processes, such as power metallurgy, ${ }^{11-14}$ the solgel method ${ }^{15-17}$ hydrothermal ${ }^{18,19}$ and electrochemical deposition. ${ }^{20-22}$ Among those processes, power metallurgy was the most frequently studied for producing the $\mathrm{Cu}-\mathrm{Gr}$ composite, in which Gr is mixed with copper powders and composites obtained by hot pressing sintering. ${ }^{23}$ The sol-gel method refers to

${ }^{a}$ School of Physics and Technology, MOE Key Laboratory of Artificial Micro- and Nano-Structures, Wuhan University, Wuhan, 430072, China. E-mail: cxpan@whu. edu.cn; Tel: $+86-27-68752481$ ext. 8168

${ }^{b}$ Center for Electron Microscopy, Wuhan University, Wuhan, 430072, China a process in which $\mathrm{Gr}$ and metal alkoxide are dissolved into organic solvents to form a homogeneous solution, and then the other components are added for a reaction to form a gel at certain temperatures, and finally dry products. The hydrothermal method is a process in which a specific metal is added into a $\mathrm{Gr}$ suspension, reacting under conditions of high temperature and high pressure in a sealed pressure vessel. However, only a few studies are related to the preparation of Grcopper $(\mathrm{Cu})$ composite foil by electrochemical deposition.

It has been recognized that adding $\mathrm{Gr}$ into the copper matrix will greatly affect the mechanical and electric performance of the composites. However, for the preparation of the electrodeposited $\mathrm{Cu}-\mathrm{Gr}$ composite foil, there are two critical problems still unsolved: (1) the direct and accurate determination of the amount of $\mathrm{Gr}$ in the foil; (2) the relationship between the concentration of $\mathrm{Gr}$ or graphene oxide (GO) in the electrolyte and the amount of $\mathrm{Gr}$ in the foil. Obviously, the solution of these problems will have a great significance for the applications of graphene in composites.

Recently, most research has indirectly determined the relationship between the performance of the $\mathrm{Cu}-\mathrm{Gr}$ composite foil and the Gr content by adjusting the concentration of $\mathrm{Gr}$ or GO in the electrolyte. For instance, Pavithra et al. ${ }^{24}$ prepared $\mathrm{Cu}-\mathrm{Gr}$ composite foils by pulse reverse electrochemical deposition. 
Compared with a pure $\mathrm{Cu}$ foil, the hardness and elastic modulus of the $\mathrm{Cu}-\mathrm{Gr}$ foil increased by $96 \%$, but the electric conductivity decreased by $35 \%$. They found that the optimal concentration of GO in the electrolyte (from $0.1 \mathrm{~g} \mathrm{~L}^{-1}$ to $1.0 \mathrm{~g}$ $\mathrm{L}^{-1}$ ) was $0.5 \mathrm{~g} \mathrm{~L}^{-1}$. Jagannadham ${ }^{25-27}$ prepared $\mathrm{Cu}-\mathrm{Gr}$ composites at a low current density of $1.75 \mathrm{~mA} \mathrm{~cm}^{-2}$ by electrochemical co-deposition. An indirect method, named effective mean field analysis (EMA), was used to determine the volume fraction of $\mathrm{Gr}$ in the composites. It was found that the thermal conductivity of $\mathrm{Cu}-\mathrm{Gr}$ foils decreased from $510 \mathrm{~W} \mathrm{~m}^{-1} \mathrm{~K}^{-1}$ at $250 \mathrm{~K}\left(-23{ }^{\circ} \mathrm{C}\right)$ to $440 \mathrm{~W} \mathrm{~m}{ }^{-1} \mathrm{~K}^{-1}$ at $350 \mathrm{~K}\left(77^{\circ} \mathrm{C}\right)$ and the resistivity of electrolytic $\mathrm{Cu}$ was reduced by $10-20 \%$ with the addition of $8-11 \% \mathrm{Gr}$ volumes. Xie et al. ${ }^{28}$ adopted cyclic voltammetry (CV) to define the electrochemical deposition conditions in $\mathrm{CuSO}_{4}$ solutions, including GO concentrations ranging from $0.1 \mathrm{mg} \mathrm{mL}^{-1}$ to $0.5 \mathrm{mg} \mathrm{mL}^{-1}$. The electrical and electroactive properties of the $\mathrm{Cu}-\mathrm{Gr}$ composite foils were investigated. The results showed that compared with polished $\mathrm{Cu}$ foil and electrodeposited $\mathrm{Cu}$ foil, the $\mathrm{Cu}-\mathrm{Gr}$ composite foils maintained a lower electrical resistivity. The order of the electroactivity was polished $\mathrm{Cu}$ foil $>$ $\mathrm{Cu}-\mathrm{Gr}$ composite foil > electrodeposited $\mathrm{Cu}$ foil. Huang et al. ${ }^{29}$ also prepared $\mathrm{Cu}-\mathrm{Gr}$ composite foil by using a pulse current electrochemical deposition and adding different amounts of $\mathrm{Gr}$ from $0.05 \mathrm{~g} \mathrm{~L}^{-1}$ to $0.3 \mathrm{~g} \mathrm{~L}^{-1}$ to the electrolyte. The results revealed that the $\mathrm{Cu}-\mathrm{Gr}$ composite had an equal resistivity to $\mathrm{Cu}$, and the tensile strength and yield strength increased by $21.1 \%$ and $39.1 \%$, respectively.
In general, for practical applications, it is best to know the $\mathrm{Gr}$ content in the composite foil and to measure its influence on the foil's mechanical and electrical properties. In this paper, we prepared $\mathrm{Cu}-\mathrm{Gr}$ composite foils through direct current electrochemical deposition, and firstly proposed a direct approach to accurately determine the amount of Gr in the foil through the measurement of the carbon (C) content in the foil by using a high frequency infrared carbon and sulfur analyzer. Simultaneously, the relationship between the Gr content in the foils and the corresponding GO concentration in the electrolyte was figured out. Due to the complexity of the electrochemical process and numerous influencing factors on the amount of $\mathrm{Gr}$ in the foils, we only investigated the relationship between the $\mathrm{Gr}$ content in the foils and concentration of GO in the electrolyte under certain constant parameters, and the effects of other possible factors will be studied in our following work.

\section{Experimental section}

All experimental reagents were of analytical grade and deionized water was utilized to prepare the electrolyte. Graphene oxide (GO) was synthesized from natural graphite powders by a modified Hummers' method. ${ }^{30}$ The $\mathrm{Cu}-\mathrm{Gr}$ composite foils were prepared by using direct current electrochemical deposition in an electrolytic bath consisting of $250 \mathrm{~g} \mathrm{~L}^{-1} \mathrm{CuSO}_{4}$ and $130 \mathrm{~g} \mathrm{~L}^{-1} \mathrm{H}_{2} \mathrm{SO}_{4}$. In order to avoid the agglomeration of GO during deposition, $50 \times N$ ppm surfactant polyacrylic acid (PAA
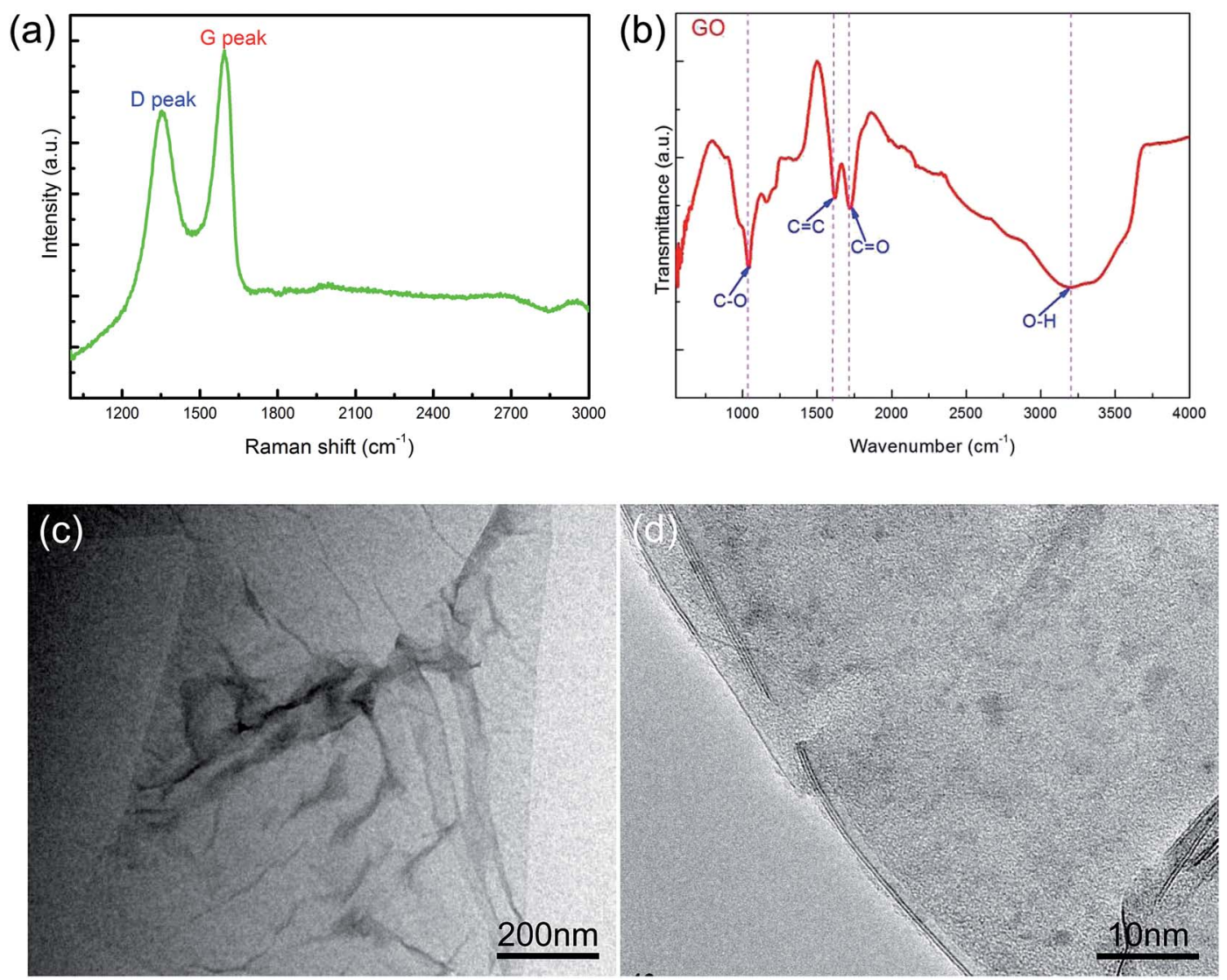

Fig. 1 Characterization of the GO. (a) Raman spectrum; (b) FT-IR spectrum; (c) TEM image; (d) HRTEM image. 

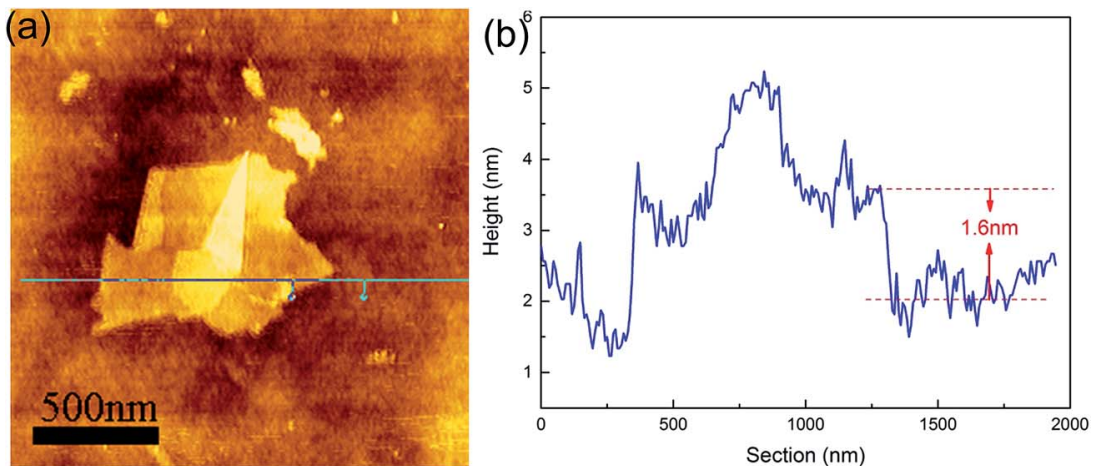

Fig. 2 (a) AFM image and (b) its height profile of the GO.

$5000)$ was added into the electrolyte, where $N$ is the concentration of GO (from $0.05 \mathrm{~g} \mathrm{~L}^{-1}$ to $1 \mathrm{~g} \mathrm{~L}^{-1}$ ). The bath temperature was maintained between 20 and $25{ }^{\circ} \mathrm{C}$. The 30 micron composite foils were achieved under conditions of magnetic stirring, when the current density and deposition time were $5 \mathrm{~A}$ $\mathrm{dm}^{-2}$ and 30 minutes, respectively. For comparison, electrodeposited pure $\mathrm{Cu}$ foil was also prepared by using the same electrolyte without the addition of GO.

Carbon content measurements of the $\mathrm{Cu}-\mathrm{Gr}$ foils were made by using a frequency infrared carbon and sulfur analyzer (CS-206, Shanghai Baoying Tech Co., Ltd., China) with an accuracy of $1.0 \mathrm{ppm}$. The morphologies and chemical compositions of the samples were characterized by a scanning electron microscope (SEM) (S-4800, Hitachi, Japan, and SIRON, FEI, The Netherlands) equipped with an energydispersive X-ray spectroscope (EDS); transmission electron microscope (TEM, JEM-2100, JEOL, Japan) with an acceleration voltage of $200 \mathrm{kV}$; high-resolution transmission electron microscopy (HRTEM) (JEM 2010 FEF-HRTEM, JEOL, Japan); a laser scanning confocal micro-Raman spectrometer (LabRAM HR, HORIBA, France) with a laser excitation wavelength of $488 \mathrm{~nm}$ and scans on an extended range of 1000-3000 $\mathrm{cm}^{-1}$; a Fourier transform infrared spectrometer (FT-IR, Nicolet iS10, Thermo Fisher, USA) with a scanning range of $525-4000 \mathrm{~cm}^{-1}$; an X-ray photoelectron spectroscope (XPS, ESCALAB 250Xi, Thermo Fisher, USA) with Al Ka radiation of $1486.6 \mathrm{eV}$ as the excitation source; an atomic force microscope (AFM, Multimode 8, Bruker, Germany) with scan assist-air probe under peak force mode in ambient conditions.

The hardness and elastic modulus of the samples were measured using an instrumental nanoindenter (Agilent G200 Nanoindenter, Agilent Technologies, USA). The CSM standard hardness and modulus test programs were used, in which the harmonic depth and frequency were $2 \mathrm{~nm}$ and $45 \mathrm{~Hz}$, respectively. The maximum indentation depth was $2000 \mathrm{~nm}$. For each sample, 10 points were tested to get an average value. The tensile strength of the samples was measured by an electronic universal testing machine (model CMT6203, MTS systems Co., Ltd.) in accordance with the testing method IPC-TM-650, where the width of the samples was $12.7 \mathrm{~mm}$ and the tensile rate was $2 \mathrm{~mm} \mathrm{~min}^{-1}$.
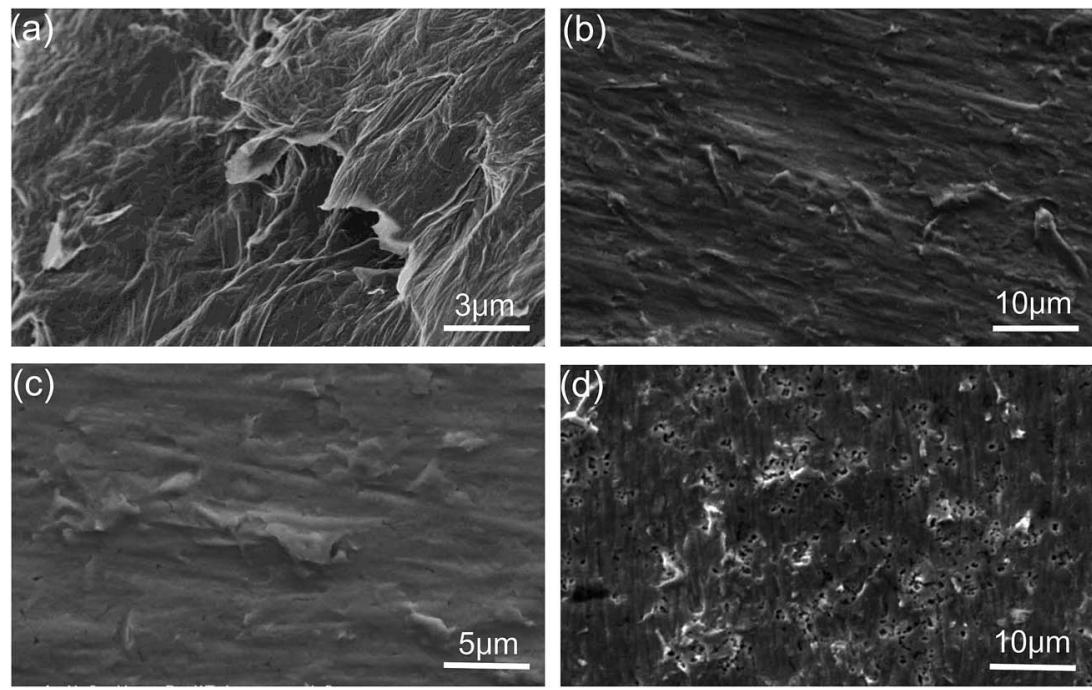

Fig. 3 SEM images of the samples. (a) GO; (b) $\mathrm{Cu}-\mathrm{Gr}$ composite foil etched in $\mathrm{HCl}$ and $\mathrm{FeCl}_{3}$ solution; (c) high magnification of the foil; (d) pure copper foil etched in $\mathrm{HCl}$ and $\mathrm{FeCl}_{3}$ solution. 

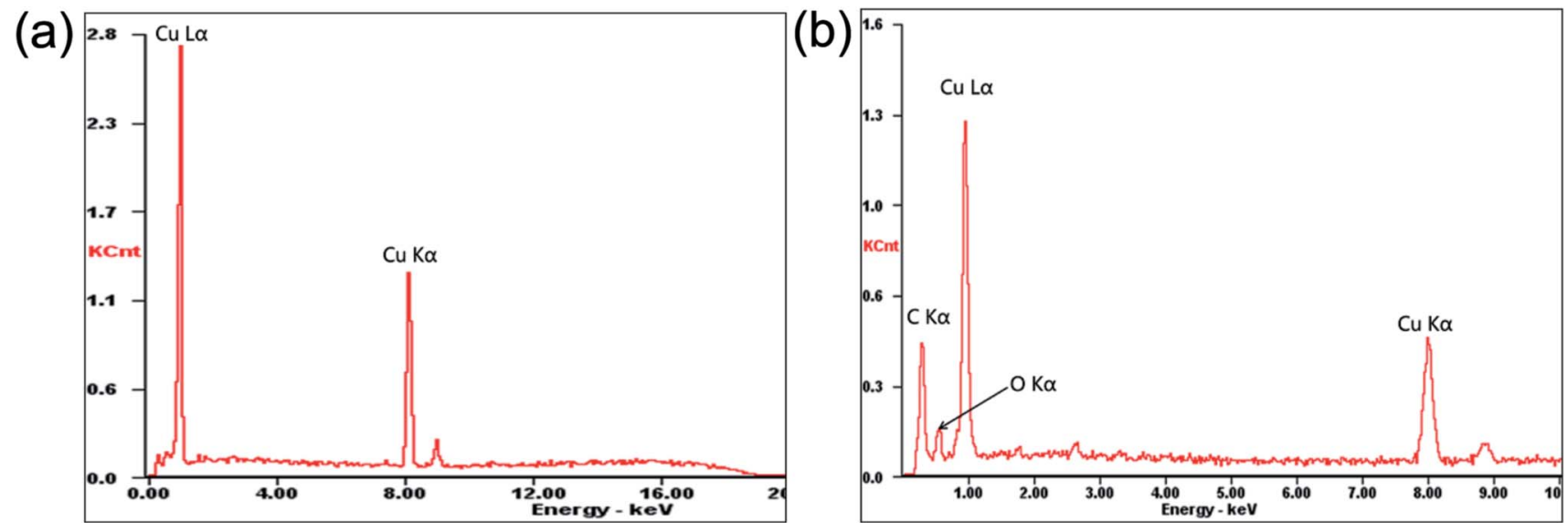

Fig. 4 EDS spectra of the samples. (a) Pure Cu foil; (b) Cu-Gr composite foil.

\section{Results and discussion}

Fig. 1 shows the characterizations of the GO by using Raman and FT-IR spectrometers and TEM. The Raman spectra showed a D peak at $1361.8 \mathrm{~cm}^{-1}$, a G peak at $1594.9 \mathrm{~cm}^{-1}$, and the $I_{\mathrm{D}} / I_{\mathrm{G}}$ ratio was 0.84 , which revealed the defects in GO. The FT-IR result showed the characteristic peaks, i.e., $\mathrm{O}-\mathrm{H}$ stretching vibration at $\approx 3189 \mathrm{~cm}^{-1}, \mathrm{C}=\mathrm{O}$ (carboxyl/carbonyl) stretching at $\approx 1720 \mathrm{~cm}^{-1}, \mathrm{C}=\mathrm{C}$ (aromatic ring) at $\approx 1620$ $\mathrm{cm}^{-1}$, and $\mathrm{C}-\mathrm{O}$ (alkoxy) stretching at $\approx 1043 \mathrm{~cm}^{-1}$, corresponding to the typical peaks of GO. The TEM image showed that the GO exhibited a kind of layered structure, and HRTEM observation revealed that it was a bilayer GO. AFM measurement indicated that the GO thickness was about $1.6 \mathrm{~nm}$, as shown in Fig. 2, which also confirmed a bilayer structure for the GO.

Fig. 3 shows the SEM images of the GO, pure $\mathrm{Cu}$ foil and composite foil prepared by electrochemical deposition. Clearly, GO presented a sheet morphology with wrinkles on the surface, so that it could be dispersed uniformly in the electrolyte. In the $\mathrm{Cu}-\mathrm{Gr}$ foil, the layered $\mathrm{Gr}$ structures were observed on the etched surface, but the layered Gr was not found in the pure $\mathrm{Cu}$ foil. In addition, it was noted that after etching, the $\mathrm{Cu}-\mathrm{Gr}$ foil exhibited stronger corrosion resistance than the pure $\mathrm{Cu}$ foil in hydrochloric acid, because there were a lot of etching holes on the surface of the pure $\mathrm{Cu}$ foil, while there were very few holes on the surface of the $\mathrm{Cu}-\mathrm{Gr}$ foil. EDS chemical composition analysis revealed that only the peaks of $\mathrm{Cu} L \alpha$ and $\mathrm{Cu} \mathrm{K} \alpha$ were
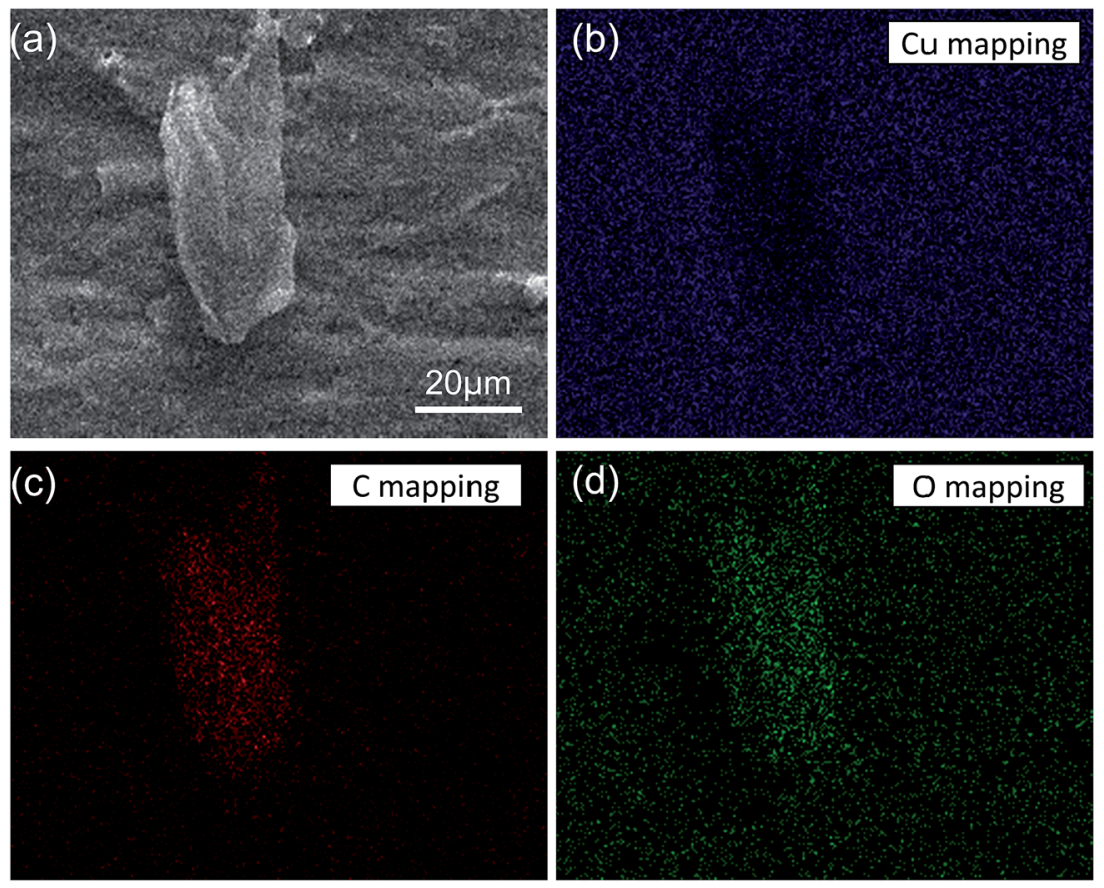

Fig. 5 EDS elemental mapping analysis of the $\mathrm{Cu}-\mathrm{Gr}$ composite foil. (a) SEM image; (b) Cu element; (c) $\mathrm{C}$ element; (d) $\mathrm{O}$ element. 

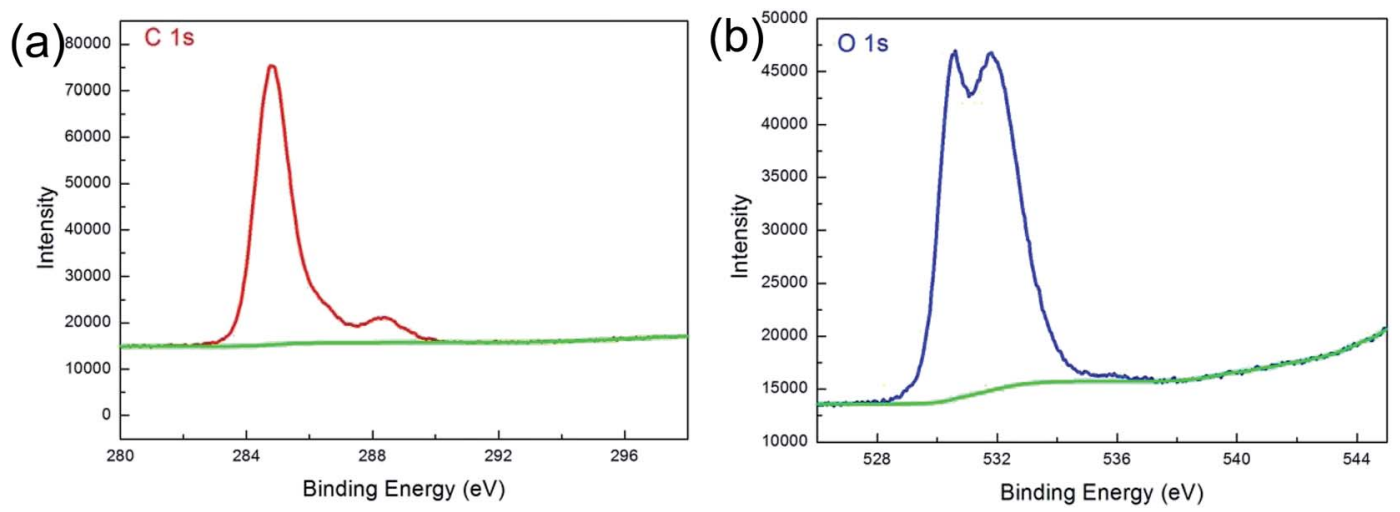

Fig. 6 XPS spectra of the Cu-Gr composite foil. (a) C 1s; (b) O 1s.

observed for the pure $\mathrm{Cu}$ foil; while an additional relatively strong peak of $\mathrm{C} \mathrm{K} \alpha$ and a weak peak of $\mathrm{O} \mathrm{K} \alpha$ existed for the composite foil, as shown in Fig. 4. This result further indicated that GO has been co-deposited into the composite foil, but the amount was low.

Fig. 5 shows the EDS mapping of the element distributions in the $\mathrm{Cu}-\mathrm{Gr}$ foil. It can be seen that the $\mathrm{Cu}, \mathrm{C}$ and $\mathrm{O}$ elements were distributed uniformly in the foil, and a few Gr aggregated in some areas, which demonstrated that GO has been codeposited uniformly in the $\mathrm{Cu}-\mathrm{Gr}$ foil. This was because the hydrophilicity of GO was improved by oxygen functional groups like carboxylic acid, and GO could also suspend stably in the electrolyte due to the addition of a few proper surfactants. However, during electrochemical deposition, GO was reduced partially to $\mathrm{Gr}$ at high current, ${ }^{28}$ which decreased the oxygen functional groups and increased the hydrophobicity of GO, so that it was easier to form GO agglomerations.
Fig. 6 illustrates XPS spectra of the composite foil. For the C $1 \mathrm{~s}$ spectrum, the main peak at $284.8 \mathrm{eV}$ is the $\mathrm{sp}^{2}$-bonded carbon, and the minor peaks at $288.6 \mathrm{eV}$ represent the $\mathrm{O}-\mathrm{C}=\mathrm{O}$ bonds. Correspondingly, the $\mathrm{O} 1 \mathrm{~s}$ spectrum can be divided into two peaks with binding energies of 530.61 and $531.8 \mathrm{eV}$, which can be assigned to the $\mathrm{Cu}_{2} \mathrm{O}$ and $\mathrm{O}-\mathrm{C}=\mathrm{O}$ bonds, respectively. ${ }^{28}$ The XPS measurements revealed that the $\mathrm{C} / \mathrm{O}$ ratio was 2.73 for Gr in composite foil, and 1.14 for original GO, which indicated that the GO had been reduced during the process.

Fig. 7 shows the cross sections of pure $\mathrm{Cu}$ foil and the composite foil after tensile failure. It was found that the facture surface of the composite foils was significantly different from that of pure $\mathrm{Cu}$ foil. That is, the dimples in the composite foil revealed a higher ductility than pure $\mathrm{Cu}$ foil. It seemed that the GO exhibited an adhesive effect on the composite foil, and improved the tensile strength. More in-depth work is being carried out in our further experiments.
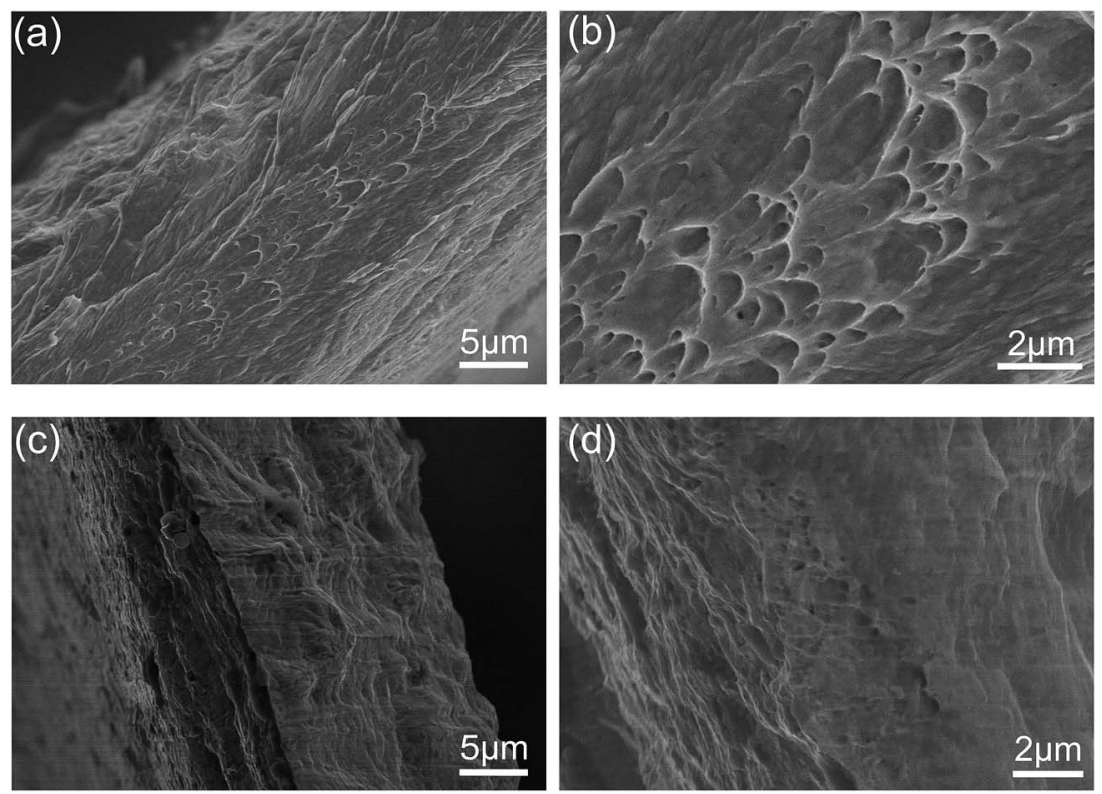

Fig. 7 SEM images of the tensile facture surfaces from the cross section of the foils. (a) Low magnification and (b) high magnification of the composite foil; (c) low magnification and (d) high magnification of pure copper foil. 


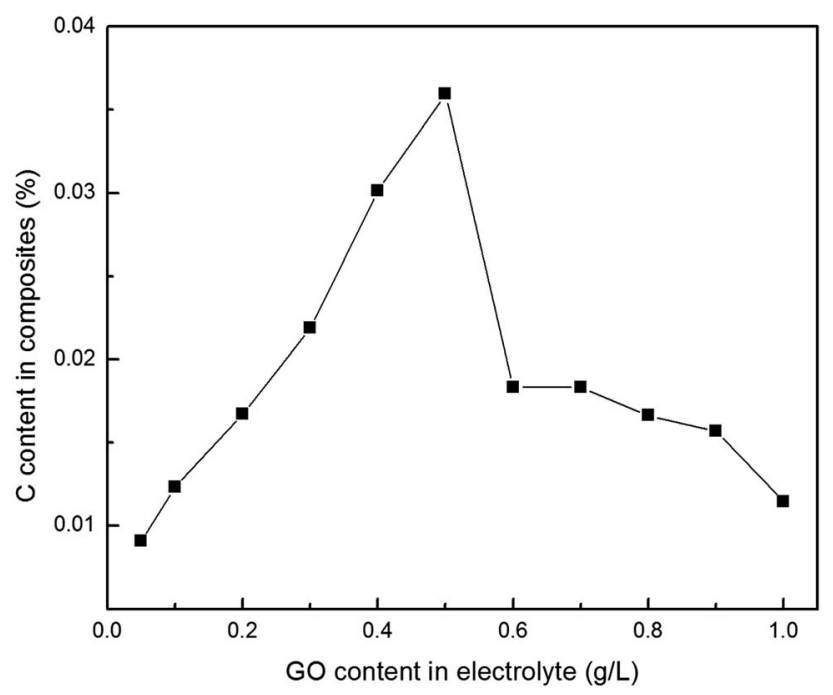

Fig. 8 Relationship between the GO concentrations in the electrolyte and the $\mathrm{C}$ content in the $\mathrm{Cu}-\mathrm{Gr}$ composite foil.

It is well known that besides the homogeneous distribution of $\mathrm{Gr}$ in the composite, its amount is also a main factor affecting the performance of the composite. So far, most research work estimates the $\mathrm{Gr}$ content and its influence on the property of the composite indirectly by controlling the concentration of $\mathrm{Gr}$ or
GO in the electrolyte. ${ }^{24,28,29}$ However, at present electrochemical deposition is a complex process, because $\mathrm{Cu}$ ions $(+0.34 \mathrm{~V})$ and Gr $(+1.2 \mathrm{~V})$ deposit at different sedimentation potentials. Therefore $\mathrm{Cu}$ and $\mathrm{Gr}$ do not deposit and reduce at the same time. That is to say, during the deposition, the relationship between the amount of Gr in the foil and Gr (or GO) in the electrolyte is not necessarily linear. Strictly speaking, the amount of $\mathrm{Gr}$ in the foil should be determined directly and accurately in order to reveal the exact effect on the performance of the composite foil.

In this work, we present an approach to directly and accurately determine the $\mathrm{Gr}$ amount in the $\mathrm{Cu}-\mathrm{Gr}$ composite foil through the measurement of carbon content in the foil by using a hypersensitized carbon and sulfur analyzer, which is commonly used in the iron and steel industry for chemical composition analysis. The working principle of the carbon and sulfur analyzer is as follows: firstly the refined carrier gas (oxygen gas) is passed into the burner (a resistance furnace or high-frequency furnace), and then the carbon and sulfur elements in the samples will be oxidized into $\mathrm{CO}, \mathrm{CO}_{2}$ and $\mathrm{SO}_{2}$. These gas mixtures are transported into a sulfur detection pool in order to determine the amount of sulfur. Subsequently, gas mixtures are further oxidized in order to convert $\mathrm{CO}$ into $\mathrm{CO}_{2}$ and transported into the carbon detection pool to determine the amount of carbon. The residual gas is discharged into the outside. The accuracy grade of this equipment can be up to ppm for measurements of carbon and sulfur. (a)

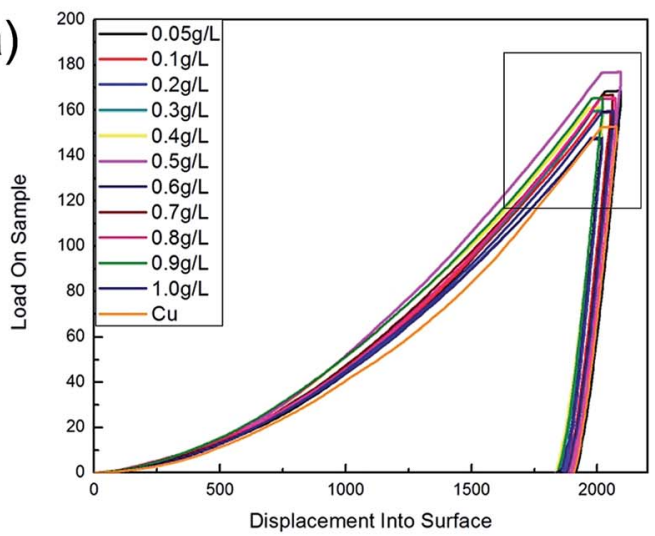

(c)

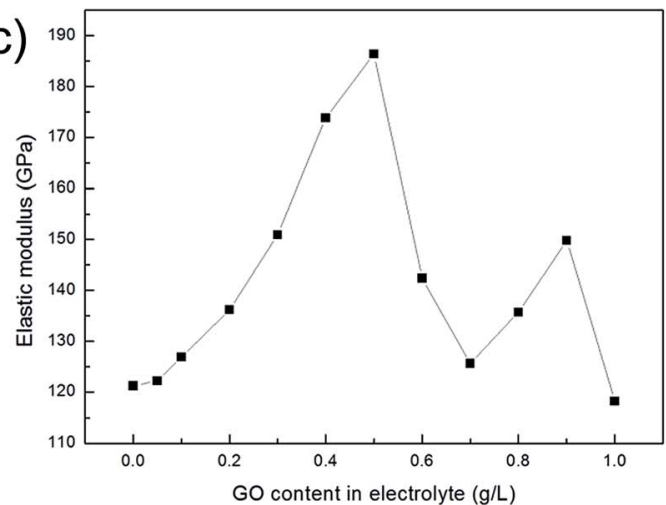

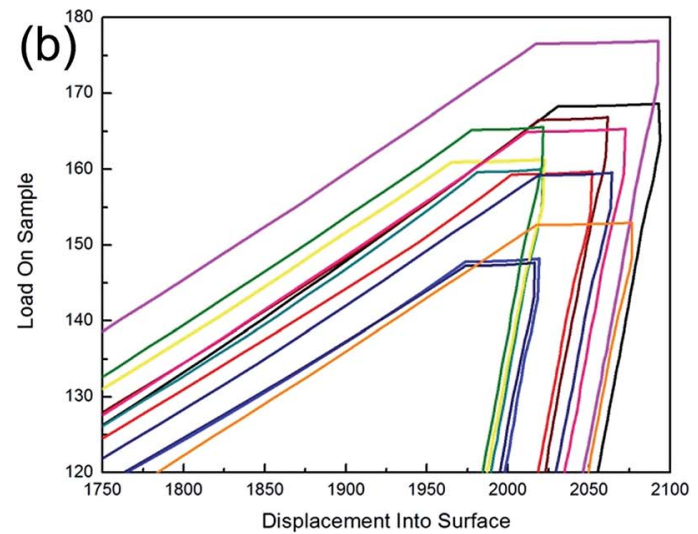

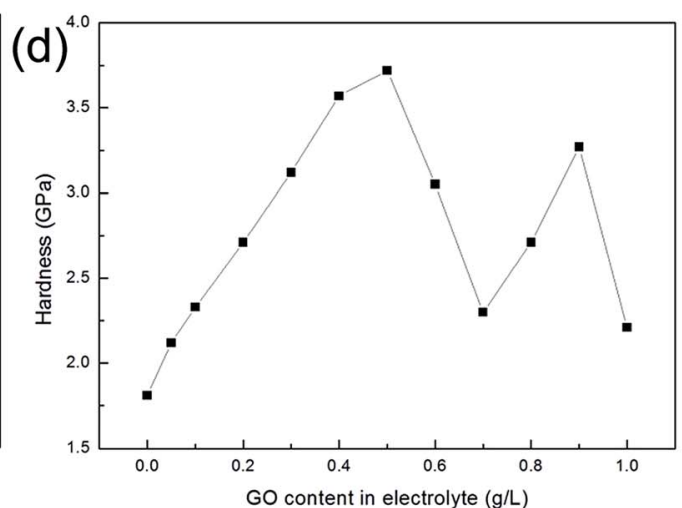

Fig. 9 Nanoindentation measurements of the samples. (a) Load-displacement curves; (b) partial enlarged drawing; (c) elastic modulus; (d) hardness. 

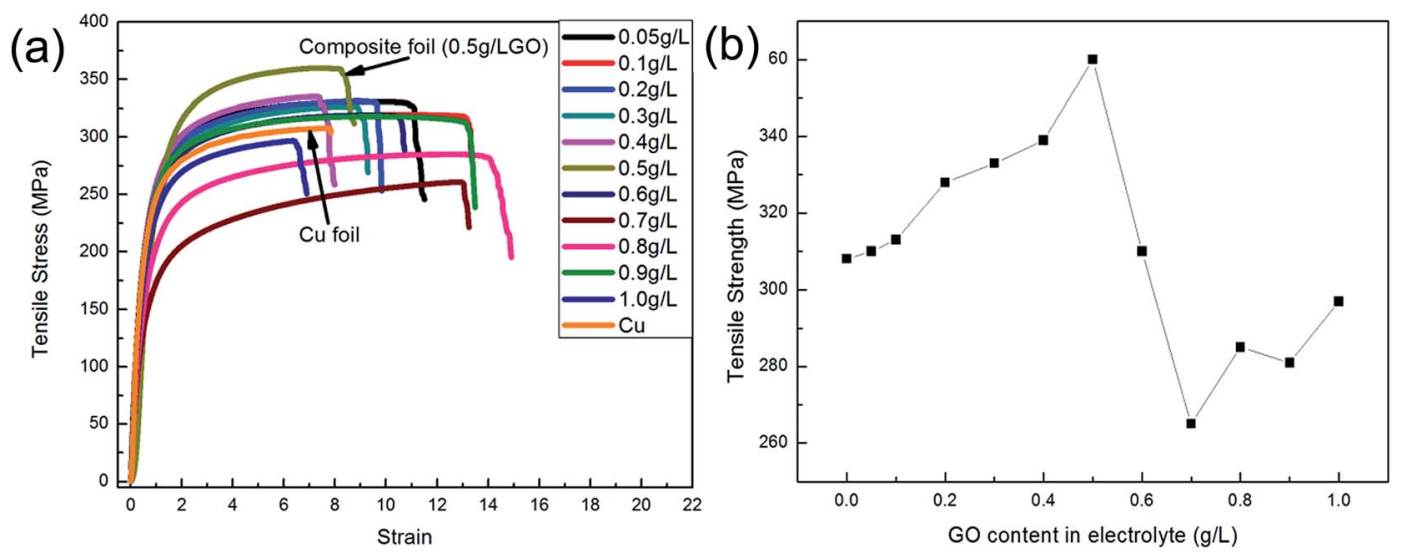

Fig. 10 Tensile test of the samples. (a) Stress-strain curves; (b) tensile strength.

In addition, establishing the relationship between the concentration of Gr (or GO) in the electrolyte and the amount of co-deposited $\mathrm{Gr}$ in the composites also has great value both in theory and in practice. Fig. 8 illustrates the relationship between the GO concentrations in the electrolyte and the $\mathrm{Gr}$ content in the composite foils. It was found that with a sequential increase in the GO concentration in the electrolyte, the amount of carbon (C) in the composite foils increased at first and then decreased. And the first portion exhibited an approximately linear relationship with a slope of 0.0595 , which revealed that the $\mathrm{C}$ content in the foil increased slowly along with the increase in GO concentration in the electrolyte. After the amount of co-deposited $\mathrm{Gr}$ reached its maximum value (about $\mathrm{C}=0.03594 \mathrm{wt} \%$ ) at $0.5 \mathrm{~g} \mathrm{~L}^{-1} \mathrm{GO}$ concentration in the electrolyte, with a further increase in GO concentrations in the electrolyte, the Gr content in the foil showed an abrupt downward trend at first, and then continued down. This is because the rheological behaviour of the electrolyte changed with an increase in the GO concentration. That is to say, the dominant interparticle forces, including electrostatic repulsive forces and van der Waals forces, change according to the GO concentration in the electrolyte during electrodeposition. Considering the complex hydrodynamic interactions, we propose the following possible changes: (1) in the range $0.1-0.5 \mathrm{~g} \mathrm{~L}^{-1}$, electrostatic repulsive forces play a leading role, because GO with charged ions disperses uniformly under the presence of a surfactant. (2) However, when the concentration is higher than $0.5 \mathrm{~g} \mathrm{~L}^{-1}$, the dominant interparticle force gradually becomes the van der Waals force because of the over high surface Gibbs free energy of GO. Thus, when the concentration of GO in the electrolyte is excessive, despite the presence of a surfactant, the oversized GO agglomerations occurred and the GO dispersion in the electrolyte also became worse. In this way, these agglomerations would be easier to be desorbed from the cathode under the strong convection, so that they were more difficult to capture into the composite foil. ${ }^{31}$

Fig. 9 and 10 show the changes in mechanical properties of the composite foils with an increase in the GO concentration in the electrolyte. Obviously, compared to Fig. 8, the values of elastic modulus, hardness and tensile strength exhibited similar tendencies with variations in the GO concentration in the electrolyte. That is to say, when the GO concentration was up to $0.5 \mathrm{~g} \mathrm{~L}^{-1}$ in the electrolyte, the amounts of $\mathrm{C}$ or $\mathrm{Gr}$ in the foils were at their highest, and the corresponding mechanical properties also reached their maximum values, which is coincident with the results of many studies. ${ }^{20,24,32}$ However, when the GO concentration in the electrolyte further increased, the decrease in the co-deposited $\mathrm{Gr}$ in the foil resulted in a decrease in its mechanical properties. Actually, at a high concentration of GO in the electrolyte, the mechanical properties of the foils were unstable due to the GO agglomerations and the complexity of electrochemical deposition. This phenomenon suggested that the GO concentration in the electrolyte should not be too high.

\section{Conclusions}

(1) A Cu-Gr composite foil was prepared by using direct current electrochemical deposition. The amount of $\mathrm{Gr}$ in the foil was directly and accurately determined through measurement of the carbon (C) content in the foil by using a high frequency infrared carbon and sulfur analyzer. And the relationship between the Gr content in the foils and the corresponding GO concentration in the electrolyte was obtained for the first time.

(2) The variations in mechanical properties involving elastic modulus, hardness and tensile strength of the $\mathrm{Cu}-\mathrm{Gr}$ foils were similar to the changes in amount of $\mathrm{Gr}$ in the foils with an increase in the GO concentration in the electrolyte.

(3) According to the current process, the optimal GO concentration in the electrolyte was $0.5 \mathrm{~g} \mathrm{~L}^{-1}$, which resulted in a maximum value of corresponding amount of C (0.03594 wt\%) in the foil and the highest mechanical properties of the foil. However, excessive GO concentration in the electrolyte would cause agglomeration and make it more difficult for codeposition into the foil. Compared with the pure $\mathrm{Cu}$ foil, the $\mathrm{Cu}-\mathrm{Gr}$ foil exhibited a great enhancement in mechanical properties and had optimum values.

(4) The present approach for directly determining the amount of $\mathrm{Gr}$ in composites by using a carbon and sulfur analyzer has many advantages, such as simplicity, rapidity, high accuracy and good repeatability. It is expected to be employed in 
other areas of metal-graphene composites, and shows important significance both in investigation in the laboratory and in industrial applications.

\section{Acknowledgements}

This work was supported by the National Nature Science Foundation of China (No. 11174227), Kingboard Laminates Holdings Limited and Chinese Universities Scientific Fund. The authors would like to thank Shanghai Baoying Tech Co., Ltd. for testing cooperation.

\section{References}

1 K. S. Novoselov, V. I. Fal'ko, L. Colombo, P. R. Gellert, M. G. Schwab and K. Kim, Nature, 2012, 490, 192-200.

2 A. Majeed, W. Ullah, A. W. Anwar, F. Nasreen, A. Sharif, G. Mustafa and A. Khan, J. Alloys Compd., 2016, 671, 1-10.

3 Q. Ke and J. Wang, Journal of Materiomics, 2016, 2, 37-54.

4 H. G. P. Kumar and M. A. Xavior, Procedia Eng., 2014, 97, 1033-1040.

5 A. C. Stoot, L. Camilli, S.-A. Spiegelhauer, F. Yu and P. Bøggild, J. Power Sources, 2015, 293, 846-851.

6 Y. Luo, F. Y. Kong, C. Li, J.-J. Shi, W.-X. Lv and W. Wang, Sens. Actuators, B, 2016, 234, 625-632.

7 C. Zhang, Y. Zhang, X. Du, Y. Chen, W. Dong, B. Han and Q. Chen, Talanta, 2016, 159, 280-286.

8 X. Wang, N. Wang, T. Gong, Y. Zhu and J. Zhang, Appl. Surf. Sci., 2016, 387, 707-719.

9 Z. Li, Y. Zhou, Y. Yang and H. Dai, Mater. Des., 2016, 105, 352-358.

10 J. Hwang, T. Yoon, S. H. Jin, J. Lee, T. S. Kim, S. H. Hong and S. Jeon, Adv. Mater., 2013, 25, 6724-6729.

11 D. Zhang and Z. Zhan, J. Alloys Compd., 2016, 654, 226-233. 12 J. Li, L. Zhang, J. Xiao and K. Zhou, Trans. Nonferrous Met. Soc. China, 2015, 25, 3354-3362.

13 D. Zhang and Z. Zhan, J. Alloys Compd., 2016, 658, 663-671.
14 M. Li, H. Che, X. Liu, S. Liang and H. Xie, J. Mater. Sci., 2014, 49, 3725-3731.

15 C. Hintze, K. Morita, R. Riedel, E. Ionescu and G. Mera, J. Eur. Ceram. Soc., 2016, 36, 2923-2930.

16 Z. Tian, Z. Zhou, S. Liu, F. Ye and S. Yao, Solid State Ionics, 2015, 278, 186-191.

17 C. T. Chou, F. H. Wang and W. C. Chen, Thin Solid Films, 2016, 605, 143-148.

18 Z. L. Wu, C. K. Li, J. G. Yu and X. Q. Chen, Sens. Actuators, B, 2017, 239, 544-552.

19 W. Zhang, H. Guo, H. Sun and R. C. Zeng, Appl. Surf. Sci., 2016, 382, 128-134.

20 H. Wu, F. Liu, W. Gong, F. Ye, L. Hao, J. Jiang and S. Han, Surf. Coat. Technol., 2015, 272, 25-32.

21 J. Chen, J. Li, D. Xiong, Y. He, Y. Ji and Y. Qin, Appl. Surf. Sci., 2016, 361, 49-56.

22 C. Zhao and J. Wang, Phys. Status Solidi A, 2014, 211, 28782885.

23 W. Li, D. Li, Q. Fu and C. Pan, RSC Adv., 2015, 5, 8042880433.

24 C. L. Pavithra, B. V. Sarada, K. V. Rajulapati, T. N. Rao and G. Sundararajan, Sci. Rep., 2014, 4, 4049.

25 K. Jagannadham, Metall. Mater. Trans. A, 2012, 44, 552-559.

26 K. Jagannadham, Metall. Mater. Trans. B, 2011, 43, 316-324.

27 K. Jagannadham, J. Vac. Sci. Technol., B: Microelectron. Nanometer Struct., 2012, 30, 03D109.

28 G. Xie, M. Forslund and J. Pan, ACS Appl. Mater. Interfaces, 2014, 6, 7444-7455.

29 G. Huang, H. Wang, P. Cheng, H. Wang, B. Sun, S. Sun, C. Zhang, M. Chen and G. Ding, Microelectron. Eng., 2016, 157, 7-12.

30 Y. Gong, D. Li, Q. Fu and C. Pan, Prog. Nat. Sci.: Mater. Int., 2015, 25, 379-385.

31 H. Gül, F. Kılıç, M. Uysal, S. Aslan, A. Alp and H. Akbulut, Appl. Surf. Sci., 2012, 258, 4260-4267.

32 H. Algul, M. Tokur, S. Ozcan, M. Uysal, T. Cetinkaya, H. Akbulut and A. Alp, Appl. Surf. Sci., 2015, 359, 340-348. 